Note de lecture

Tout sur l'École, Alain Bentolila

éd. Odile Jacob, septembre 2004, 275 p.

Émile-Xavier Visseaux

(2) OpenEdition

Journals

Édition électronique

URL : http://journals.openedition.org/ries/1397

DOI : $10.4000 /$ ries. 1397

ISSN : 2261-4265

Éditeur

Centre international d'études pédagogiques

Édition imprimée

Date de publication : 1 avril 2005

Pagination : 17-18

ISSN : 1254-4590

Référence électronique

Émile-Xavier Visseaux, «Tout sur l'École, Alain Bentolila », Revue internationale d'éducation de Sèvres [En ligne], 38 | avril 2005, mis en ligne le 18 novembre 2011, consulté le 22 septembre 2020. URL : http:// journals.openedition.org/ries/1397 ; DOI : https://doi.org/10.4000/ries.1397

Ce document a été généré automatiquement le 22 septembre 2020.

(c) Tous droits réservés 


\title{
Note de lecture
}

\section{Tout sur l'École, Alain Bentolila}

éd. Odile Jacob, septembre 2004, 275 p.

\author{
Émile-Xavier Visseaux
}

\section{RÉFÉRENCE}

Tout sur l'École, Alain Bentolila, éd. Odile Jacob, septembre 2004, 275 p.

1 Au moment où le rapport Thélot, conclusif du grand débat sur l'école en France était rendu public, paraissait le livre d'Alain Bentolila au titre à la fois provocant et totalisant Tout sur l'École.

2 La compétence scientifique attestée et la connaissance approfondie du système éducatif français de ce brillant universitaire, professeur de linguistique à PARIS V, ancien instituteur, auteur de nombreux ouvrages, ne permettent pas de mettre en doute le bien fondé d'un état des lieux sans concession, débouchant sur une prospective argumentée.

3 L'ouvrage comporte quatre parties. Dans la première - « les enjeux » -, l'auteur saisit avec perspicacité une articulation désastreuse entre «l'insécurité linguistique » et la « fracture sociale» qui touche une partie importante de la population scolaire de notre pays, rendant pratiquement inaccessible l'accès au cursus scolaire proposé. Situation qui conduit de plus en plus à une "tribalisation de l'échec ", véritable contre-culture qui s'est enracinée durablement en ces milieux dits sensibles et faisant tâche d'huile. Désormais, l'échec scolaire devient une sorte d'appartenance identitaire pour nombre de jeunes (surtout les garçons) qui se font une gloire de ne pas participer à la culture générale que propose l'École.

4 Sont dénoncés, dans une seconde partie, «les ennemis de l'école » qui, de l'extérieur, provoquent et entretiennent la fracture sociale culturelle. Au premier rang, la "téléculture " avec tous ses effets dévastateurs, "l'éblouissement technologique » générateur d'illusions quant à la formation des esprits, «le repli communautaire » 
devenu un réflexe rejetant l'institution scolaire, l'école de la République, dans une démarche «insidieuse et camouflée qui lui conteste la responsabilité de légitimer ses propres valeurs ».

5 Dans la troisième partie - «trompe l'œil et faux semblants »-, l'auteur stigmatise, non sans véhémence, l'incapacité du pouvoir politique comme du système éducatif à apporter des réponses efficaces à cette évolution de société qui affecte profondément l'École. Les sous-titres sont évocateurs : «parade politique et glacis administratif », «le grand guignol de la formation des maitres », «le mythe du collège unique et de la discrimination positive ", etc.

Ces trois premières parties se proposent donc de faire l'état des lieux. Au-delà de ce qui peut, à juste titre parfois, apparaître comme partial, partiel, et où la passion de l'auteur pour une cause, où il s'est engagé sans retour, trahit peut-être désillusion et frustration, on ne peut souhaiter qu'une lecture attentive de cette analyse. Elle constitue la face, pour beaucoup cachée, de l'échec scolaire en France tel qu'il s'est consolidé depuis trois décennies, avec les fruits amers que l'on risque de récolter dans un avenir proche.

7 Suit dans une quatrième et dernière partie un véritable projet de refondation esquissé en " cinq chantiers pour une école en résistance ", à savoir : repenser l'organisation du cursus scolaire; repenser l'école maternelle; former les maîtres; sceller avec les parents un pacte de résistance ; ouvrir les portes des ghettos scolaires.

Il s'agit bien d'une refondation qui s'enracine dans la cohérence de ce qui précède et dans une vue prospective dont l'ambition se justifie, aux yeux de l'auteur, par l'ampleur des carences, blocages et dysfonctionnements constatés, comme par l'évolution rapide d'une société qui échappe de plus en plus à l'emprise de l'école.

On pourrait souhaiter que le projet soit confronté aux conclusions du rapport Thélot et que des convergences puissent être dégagées et traduites sur le plan opérationnel. Mais on peut se poser la question de la comptabilité des deux démarches. Le projet esquissé ici, véritable refondation, apparaît utopique sans un paramètre institutionnel préalable, un temps d'application garanti, à l'abri duquel il pourrait se préparer et faire son chemin dans l'opinion. L'auteur fait indirectement allusion à cette difficulté quand il écrit (p. 153) que « ministres et conseillers sont dans l'incapacité totale de se plier au temps spécifique sur lequel se construit l'histoire de l'éducation. Ils vivent dans les limites du temps de leur mandat, un temps souvent très court et dont la durée est aléatoire ». Ce qui peut expliquer et corriger le caractère abrupt d'un autre constat ( $p$. 34) : «si aujourd'hui une véritable faille culturelle fracture et pervertit notre école, c'est parce qu'aucun responsable n'a osé sacrifier le confort d'un statu quo sans cesse négocié à l'impopularité de profondes réformes nécessaires ».

Il restera à en juger au moment où le ministre de l'Éducation nationale veut par une nouvelle loi d'orientation insuffler un nouvel élan à l'école. 


\section{AUTEURS}

\section{ÉMILE-XAVIER VISSEAUX}

Inspecteur général honoraire de l'Éducation nationale 